doi:10.4149/neo_2017_102

\title{
MicroRNA-584-3p reduces the vasculogenic mimicry of human glioma cells by regulating hypoxia-induced ROCK1 dependent stress fiber formation
}

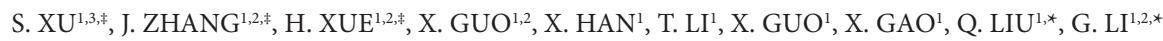 \\ ${ }^{1}$ Department of Neurosurgery, Qilu Hospital of Shandong University, 107 Wenhua Xi Road, Jinan, Shandong Province, 250012, P.R. China; \\ ${ }^{2}$ Brain Science Research Institute, Shandong University, 44 Wenhua Xi Road, Jinan, Shandong Province, 250012, P.R. China; ${ }^{3}$ Department of \\ Neurosurgery, Dezhou People's Hospital, Dezhou, Shandong Province, P.R. China
}

*Correspondence: ligangqiluhospital@163.com

${ }^{*}$ Contributed equally to this work.

Received November 1, 2015 / Accepted December 1, 2015

\begin{abstract}
We report in this study that microRNA-584-3p (miR-584-3p) is related to the vasculogenic mimicry (VM) of human glioma cells. Unsurprisingly, the postoperative survival time was significantly prolonged in those glioma patients without VM phenomena compared with those with positive VM. miR-584-3p may function as a potent tumor suppressor by inhibiting VM of malignant glioma. However, the molecular mechanisms underlying these properties remain poorly understood. Our preliminary mechanistic studies revealed that miR-584-3p suppressed the VM by disturbing hypoxia-induced stress fiber formation and migration of glioma cells. Specifically, we defined ROCK1 as a potential functionally relevant target of miR-584-3p involved in this process in glioma cells. Our results demonstrate a tumor suppressor function for miR-584-3p in glioma, where it inhibits the VM of tumor cells by antagonizing hypoxia-induced ROCK1-dependent stress fiber formation. Our findings have potential implications for glioma gene therapy by targeting miR-584-3p and suggest that VM could represent a prognostic indicator for gliomas.
\end{abstract}

Key words: microRNA, Glioma, VM, hypoxia, prognosis

Glioma, which is the most malignant tumor type, accounts for more than $70 \%$ of all brain tumors [1].The biological properties of glioma primarily include high mortality and recurrence rates, uncontrollable invasiveness, strong angiogenesis [2], and widespread hypoxia [3]. Hypoxia-induced angiogenesis a common feature in solid tumors due to their overwhelming progression and relatively inadequate blood supply. Tumor angiogenesis is an independent prognostic factor associated with poor survival [3]. Indeed, numerous studies have suggested that hypoxia activates angiogenesis and many other cellular processes [4]. However, an increasing number of studies have evaluated the roles of a new way of angiogenesis named vasculogenic mimicry (VM) in mediating the effects of hypoxia.

$\mathrm{VM}$ is a new tumor vascular pattern differently from angiogenesis [5]. It describes as a specific capacity of aggressive tumor cells to form vessel-like networks without vascular endothelial cells that provide adequate blood supply for tumor growth $[5,6]$. A variety of molecular signal pathways participate in VM induction [6], and tumor stem cells are also involved in VM formation [7]. Due to the association between VM and poor prognosis [8], some VM-related target molecules and strategies are being studied for anticancer treatment [6]. But the specific molecular mechanism of VM in glioma is still unclear.

miRNAs are a class of endogenous small non-coding RNAs that have been identified as negative regulators of gene expression at the post-transcriptional level $[9,10]$. Therefore, additional research is warranted to determine the important roles of numerous miRNAs in diverse tumor-related cellular processes, such as origin, proliferation [11], angiogenesis [12], survival [13], and metastasis [14]. However, there were only 8 miRNAs discovered targeting tumor VM, such as miR-27a [15], miR-1236 [16], miR-124 [17], miR-200a [18], miR-9 [19], miR-409-3p [20], miR-26b [21], and miR-299-5p [22], and all the miRNAs were negative regulators.

The present study is the first to report that miR-584-3p is a novel tumor suppressor and VM negative regulator for 
glioma. And our findings suggest an unexpected fundamental tumor-suppressive role for miR-584-3p in glioma due to its anti-VM effect, which is probably mediated by targeting ROCK1-dependent cytoskeleton rearrangement. Our data highlight the importance of miRNAs in tumor VM and provide new insights into understanding the molecular mechanism underlying tumor progression. Prospectively, miR-584-3p acts as a potential therapeutic target for malignant glioma.

\section{Materials and methods}

Tissue samples and cell lines. The human glioma cell lines U87 and A172 cell lines were purchased from the Chinese Academy of Sciences Cell Bank. Eighty-one human glioma tissues and 3 normal brain tissues of decompression operation were obtained from the Department of Neurosurgery of Qilu Hospital of Shandong University (Table1). The glioma specimens were verified and classified according to the WHO classification standard of tumors by two experienced clinical pathologists. Our study was approved by the Institutional Review Board of Shandong University. Written informed consent was obtained from all patients, and the hospital ethical committee approved the experiments.

Reagents and cell culture. All cells were cultured in DMEM supplemented with $10 \% \mathrm{FBS}$ and maintained at $37^{\circ} \mathrm{C}$ with $5 \%$ $\mathrm{CO}_{2}$ in a humidified chamber. Y-27632 was purchased from

Table 1. Demographic parameters of patients participating in the study

\begin{tabular}{lcc}
\hline & $\begin{array}{c}\text { NO. of Pa- } \\
\text { tients }\end{array}$ & $\mathrm{N} \%$ \\
\hline Assessable & 81 & $96.43 \%$ \\
$\quad$ Glioma & 3 & $3.57 \%$ \\
$\quad$ Normal brain tissues & & \\
Gender & 52 & $61.90 \%$ \\
$\quad$ Male & 32 & $38.10 \%$ \\
Female & & \\
Age(years) & $45.1(4 \sim 75)$ & \\
Median(range) & & \\
Pathological type & 21 & $25.00 \%$ \\
$\quad$ Astrocytoma & 12 & $14.29 \%$ \\
Anaplastic astrocytoma & 5 & $5.95 \%$ \\
Pilocytic astrocytoma & 6 & $7.14 \%$ \\
Oligodendroglioma & 4 & $4.76 \%$ \\
Anaplastic oligodendroglioma & 31 & $36.90 \%$ \\
Glioblastoma & 2 & $2.38 \%$ \\
Dysembryoplastic neuroepithelial tumor & 3 & $3.57 \%$ \\
Normal brain tissues & & \\
WHO tumor grade at diagnosis & 8 & $9.88 \%$ \\
I & 28 & $34.57 \%$ \\
II & 15 & $18.52 \%$ \\
III & 30 & $37.04 \%$ \\
IV & & \\
\hline
\end{tabular}

Selleck Chemicals (USA). Hypoxic conditions were induced by incubating the cells in a modular incubator chamber flushed with a gas mixture containing $1 \% \mathrm{O}_{2}, 5 \% \mathrm{CO}_{2}$, and $94 \% \mathrm{~N}_{2}$ at $37^{\circ} \mathrm{C}$.

Cell transfection. Mature miR-584-3p mimics, inhibitor and the scrambled control were designed and synthesized by Ribo Bio. Cell transfections and co-transfections were performed using Lipofectamine 2000 when the cells reached $70 \%$ confluence according to the manufacturer's instructions. Forty-eight hours after transfection, the glioma cells were harvested for subsequent experiments.

Cell viability assay. U87 and A172 cells were seeded in 96-well culture plates at a density of 3000 cells/well. Cell proliferation was analyzed by a Cell Counting Kit-8. Optical density was measured at $450 \mathrm{~nm}$ using a microplate reader.

Cell migration assays. Cell migration assays were performed using Transwell chambers ( $8-\mu \mathrm{m}$ pore size, Corning). In total, $5 \times 10^{4}$ transfected cells in FBS-free medium were seeded in the upper Transwell chamber. Medium containing $10 \%$ FBS was added to the lower chamber. After $12 \mathrm{~h}$, the cells that did not migrate were removed using cotton buds. The cells migrating to the lower surface were fixed, stained with crystal violet for $15 \mathrm{~min}$ and counted under a microscope.

Cytoskeleton staining assay. A172 cells were plated at 8000 cells/well on climbing pieces at the bottom of the wells of 6-well plates. Cells were fixed in $4 \%$ paraformaldehyde, permeabilized using $0.1 \%$ Triton X-100, and stained with Texas Red labelled phalloidin and DAPI.

RNA extraction and real-time quantitative PCR. Total RNA was extracted from the tissue samples and cell lines using TRIzol Reagent according to the manufacturer's protocol. Then, total RNA ( $50 \mathrm{ng}$ ) was reverse-transcribed with miR-584 -3p stem-loop RT primers or with the U6 RT primers using a ReverTra Ace qPCR RT kit according to the manufacturer's protocol to generate cDNA. Real-time PCR was performed using a SYBR Premix Ex Taq ${ }^{\mathrm{TM}}$ Kit with miR-584-3por U6 PCR primers. The reactions were performed using a Roche LightCycler 2.0 Instrument.

Immunohistochemistry staining. Human glioma tissue samples were fixed with $4 \%$ formaldehyde. Paraffin-embedded tumor tissues were sectioned, and 1mMEDTA ( $\mathrm{pH}$ 8.0) was used for antigen retrieval. Endogenous peroxidase activity was quenched by $3 \%$ hydrogen peroxide, and subsequently incubated at $4^{\circ} \mathrm{C}$ overnight with primary antibodies (Abcam: 1:300 CD34). Next, the sections were incubated with horseradish peroxidase-linked antibodies, followed by reaction with diaminobenzidine and counterstaining with PAS staining kit and then Mayer's hematoxylin. The PAS staining could identify the matrix-associated vascular channels, and to distinguish between the PAS-positive network of endothelium-lined vessels and VM, the tissue slides were immunohistochemically processed with CD34 before the PAS staining to identify endotheliums [23]. The CD34-PAS double staining, for VM PAS-positive pattern network was evaluated by the criteria of Folberg et al [24]. 
VM analysis. VM formation was tested using a commercial Matrigel matrix (BD Biosciences, France). A172 and U87 glioma cells were digested and re-suspended at $5 \times 10^{4}$ cells $/ \mathrm{ml}$ in DMEM medium containing $1 \%$ fetal bovine serum. Wells of 96-well tissue culture plates were coated with Matrigel

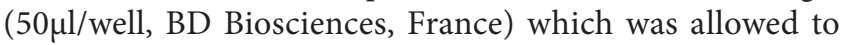
polymerase at $37^{\circ} \mathrm{C}$ for $30 \mathrm{~min}$. The glioma cell suspension was then plated at $100 \mu \mathrm{l} /$ well onto the surface of Matrigel and incubated at $37^{\circ} \mathrm{C}$.

Statistical analysis. All experiments were performed three times. The statistical analysis and experimental graphs were generated using SPSS 17.0 and Graph Pad Prism software. Descriptive statistics including the means \pm SD, Student's $t$ test, Kaplan-Meier plots, log-rank tests, one-way ANOVAs test were used to analyze the significant differences, and ${ }^{*} p<0.05$, ${ }^{* *} p<0.01,{ }^{* *} p<0.001$ was considered statistically significant.

\section{Results}

VM positive rate correlated with the WHO grades of human glioma tissues. To examine whether the VM positive rate correlates with the WHO grades of human glioma, we detected the VM in 81 human glioma specimens with different grades and 3 normal brain tissues by immunochemical staining (Table 1). As shown in Figure 1A and B, the VM had not been found in the normal brain tissues and grade I glioma tissues, except the special grade I pilocytic astrocytoma as the excessive hyperplasia of blood vessels but with less malignancy. We also found that the $\mathrm{VM}$ also rarely existed in grade II glioma tissues (Figure 1C). However, the VM phenomena were very common in high-grade (III-IV) gliomas (Figure 1D and E). Consistent with this finding, the VM positive rate of human glioma was observably associated with its WHO grades (Figure 1F).
A

A Normal brain

B

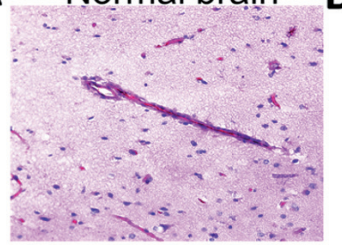

D

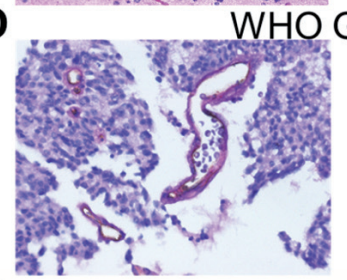

$\mathbf{F}$
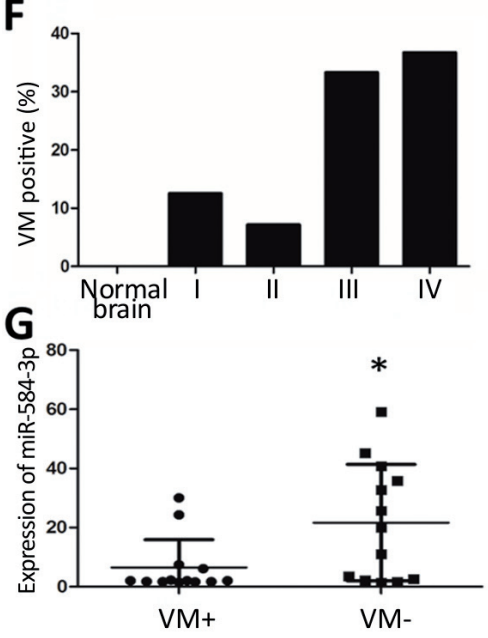

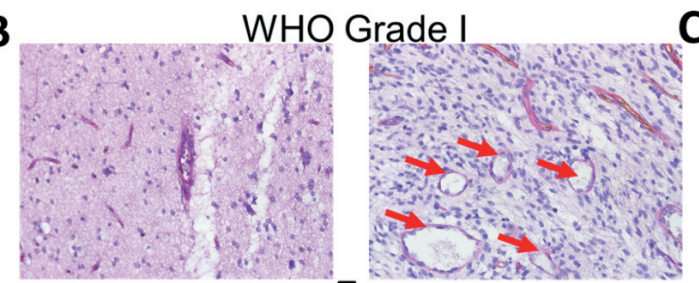

E

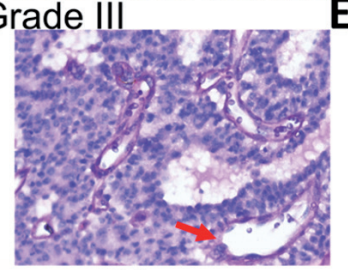

H

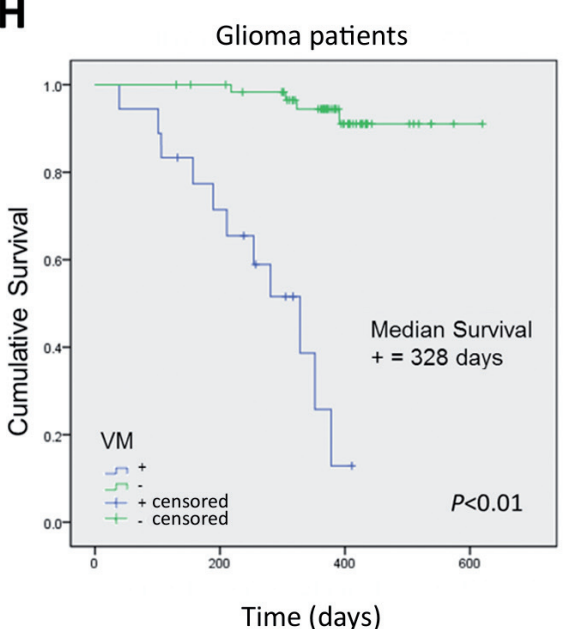

C
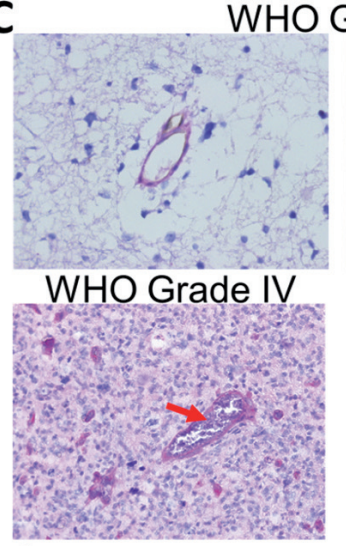

I

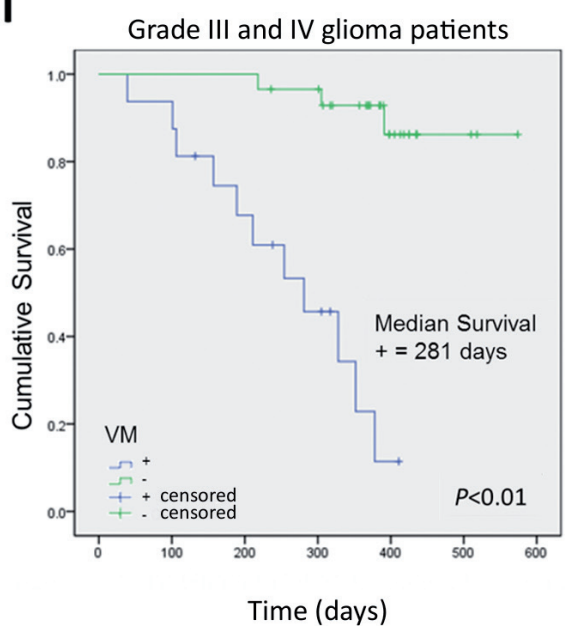

Figure 1. VM positive rate correlated with the glioma WHO grades, and VM functions as a prognostic indicator which negatively correlated with miR584-3p expression levels in human glioma tissues.

CD34-PAS immunochemical staining of normal brain (A) and grade I glioma (B), and blood vessels with endothelium. The VM in grade I pilocytic astrocytoma (right, red arrows). (C) The VM in grade II glioma tissues (right). (D) The VM in grade III glioma tissues (red arrow). (E) The VM in WHO grade IV glioma tissues (red arrows). (F)The VM positive rate of human glioma was associated with WHO grades. (G) The miR-584-3p expression levels in clinical samples from surgically removed glioma tissues of 26 patients (13gliomas with VM and 13gliomas without VM) were tested by quantitative real-time PCR. ${ }^{\star} p=0.0195$ by Mann Whitney Test. ( $\mathrm{H}$ and $\left.\mathrm{I}\right)$ Prognostic significance of VM positive rate in all glioma patients and high grade glioma patients. 
VM functions as a prognostic indicator in human glioma and negatively correlated with miR-584-3p expression levels. To analyze whether VM abundance in clinical samples associated with the clinical survival information of the 81 patients, Kaplan-Meier test were used here. It was as expected that the VM negative subgroup of glioma patients presented a significantly prolonged postoperative survival time (Figure $1 \mathrm{H})$. As the considerably higher percentage of VM-negative group in lower-grade gliomas patients, we performed the survival analyses of grade III and IV gliomas patients, to minimize the effect of confounding, and it revealed a more significant result (Figure 1I). Cell migration is an essential step in angiogenesis that promotes promotes tumor cells extending and migrating to form the neonatal VM vessels by up-regulating matrix metalloproteinases (MMPs) and epithelial marker E-cadherin
[17]. Because our previous research found miR-584-3p was a potent anti-migratory miRNAs (data not published), we suppose that miR-584-3p was probably involved in regulating VM formation. To assess the relationship between miR-584-3p and $\mathrm{VM}$, we verified the levels of miR-584-3p in 26 human glioma specimens with different grades by quantitative real-time PCR. The results showed that miR-584-3p expression levels in VM negatives group were significantly higher than the VM positive subgroup (Figure 1G). The above findings raised the intriguing possibility that miR-584-3p may act as a VM suppressor in human malignant glioma.

miR-584-3p inhibits the migratory and VM forming capacities of human glioma cells. Migration is known to play an important role in tumor $\mathrm{VM}$, and to investigate whether miR-584-3p could regulate the glioma cell migration and VM

A
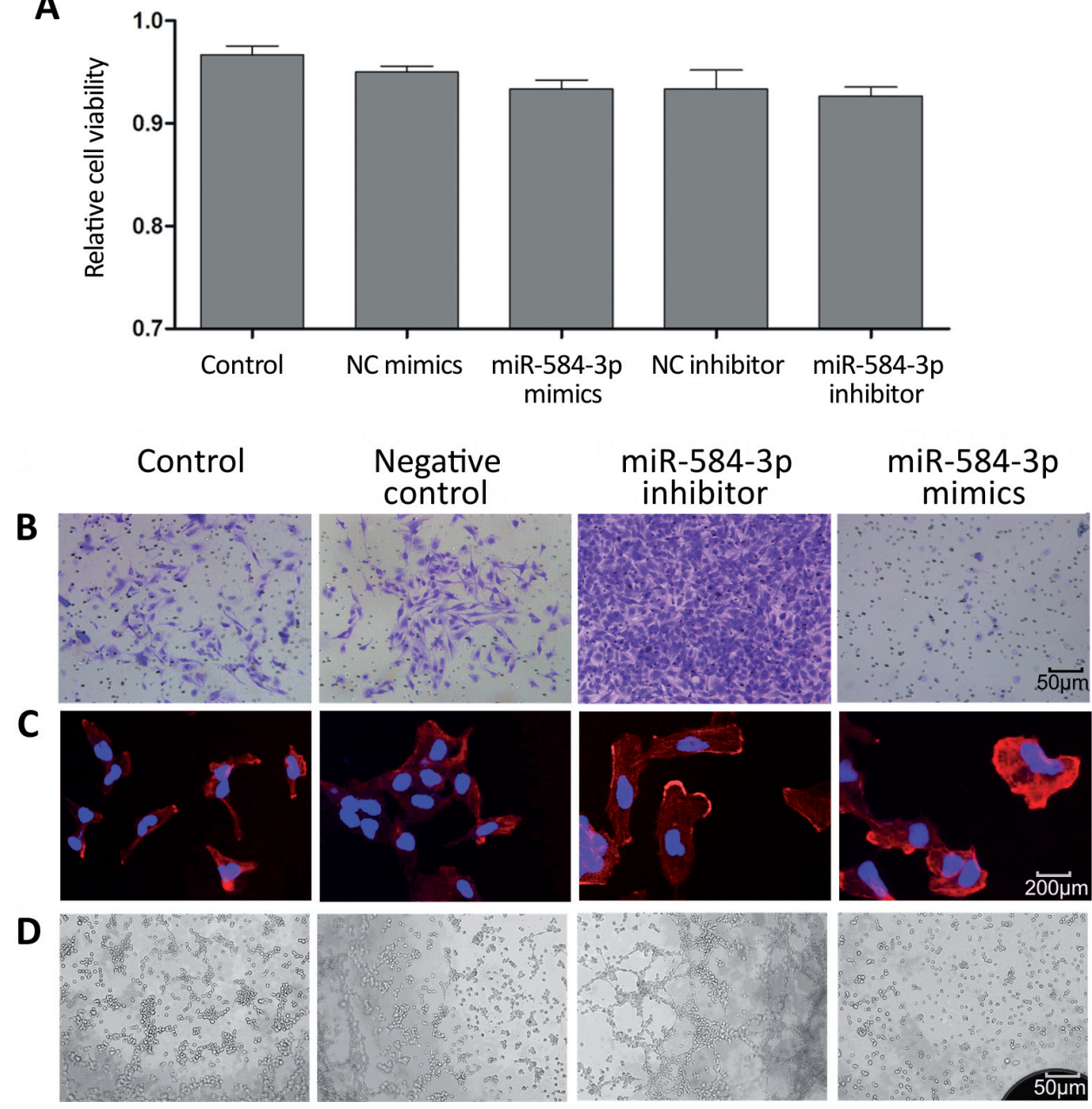

Figure 2. miR-584-3p inhibits the migratory and VM forming capacities of human glioma cells, and hypoxia promoted the VM formation.

(A) Cell viability assay of A172 cells transfected with the miR-584-3p mimics and inhibitor. (B) The pro-migratory effect of the miR-584-3p inhibitor and anti-migratory effect of the miR-584-3p mimics was examined by Transwell migration assays on A172 cell migration. (C) Effect of miR-584-3p mimics and inhibitor transfection on A172 cell stress fiber formation under normoxic conditions. The cells were fixed and stained with Texas Red phalloidin and DAPI as described in the Materials and methods. The data are representative of three independent experiments. (D) Effect of miR-584-3p mimic and inhibitor transfection on A172 cell VM formation under normoxic conditions. After the cells were transfected and incubated, they were transferred into wells of 96-well tissue culture plates were coated with Matrigel in the Materials and methods. NC, negative control. 
formation, we used the miR-584-3p inhibitor and mimics. As a proof of principle, the transient transfection of $80 \mathrm{nM}$ inhibitor or mimics did not affect glioma cell viability (Figure 2A). And we observed a significant pro-migratory effects of the miR-584-3p inhibitor and anti-migratory effects of its mimics in transwell assays of A172 cells (Figure 2B). To determine the role of miR-584-3p in motility-related morphological changes, we transiently transfected A172 glioma cells with the miR-584 $-3 p$ inhibitor or mimics and then stained them to visualize stress fibers using phalloidin as described in the Materials and methods section. Stress fiber formation involves cytoskeletal reorganization mediated by RhoA/ROCK pathway activation [25]. Our results showed that miR-584-3p knockdown facilitated stress fiber formation and the maintenance of movement morphology of glioma cells and that miR-584-3p overexpression impaired hypoxia-induced stress fiber formation (Figure 2C). VM tube formation assays confirmed that miR-584-3p knockdown significantly promoted VM formation and overexpression of miR-584-3p completely blocked it (Figure 2D). The ability of miR-584-3p to inhibit actin stress fiber formation,
A
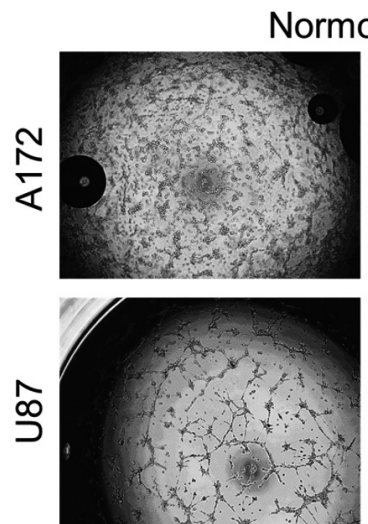

B A172 Normoxia
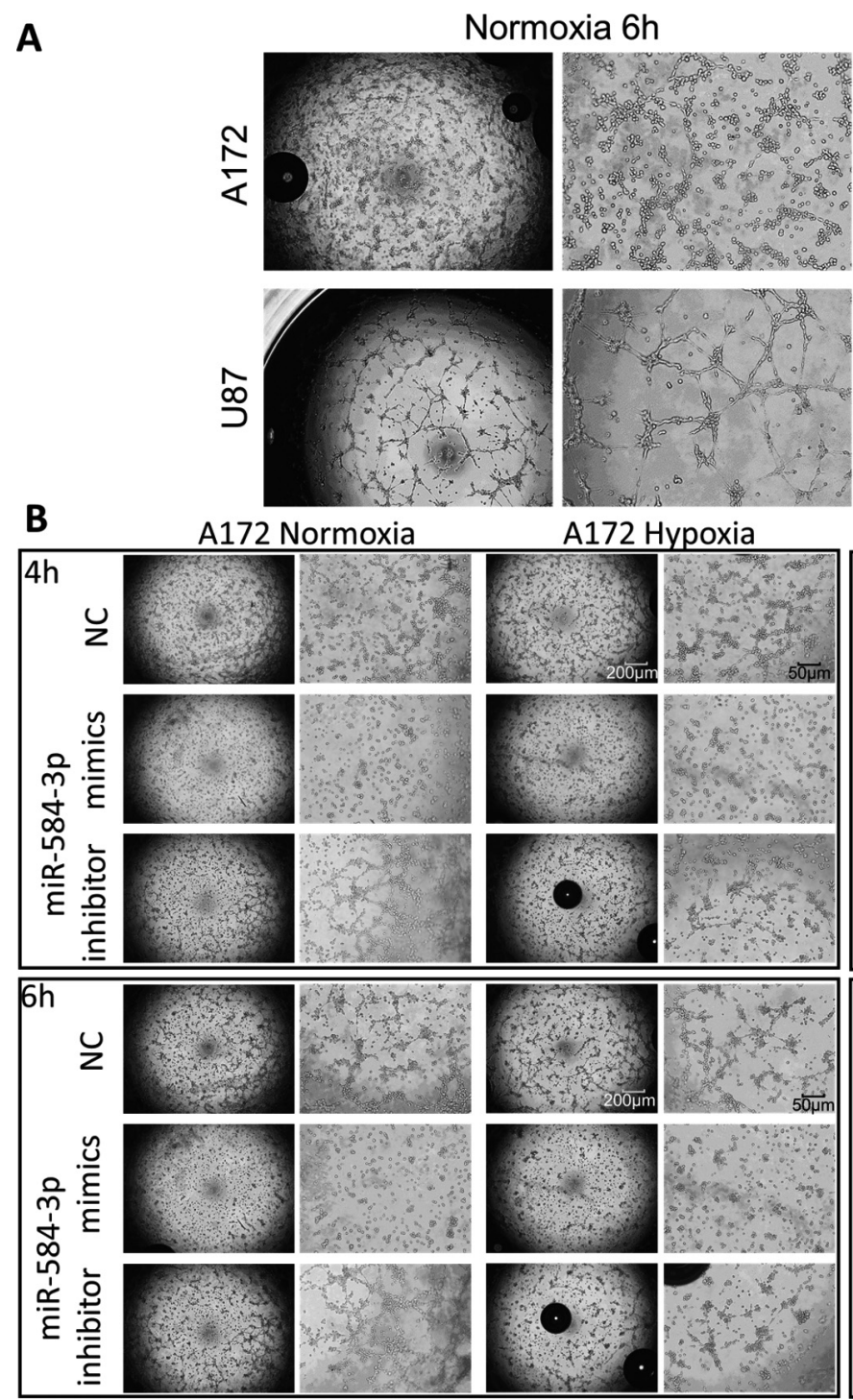

A172 Hypoxia
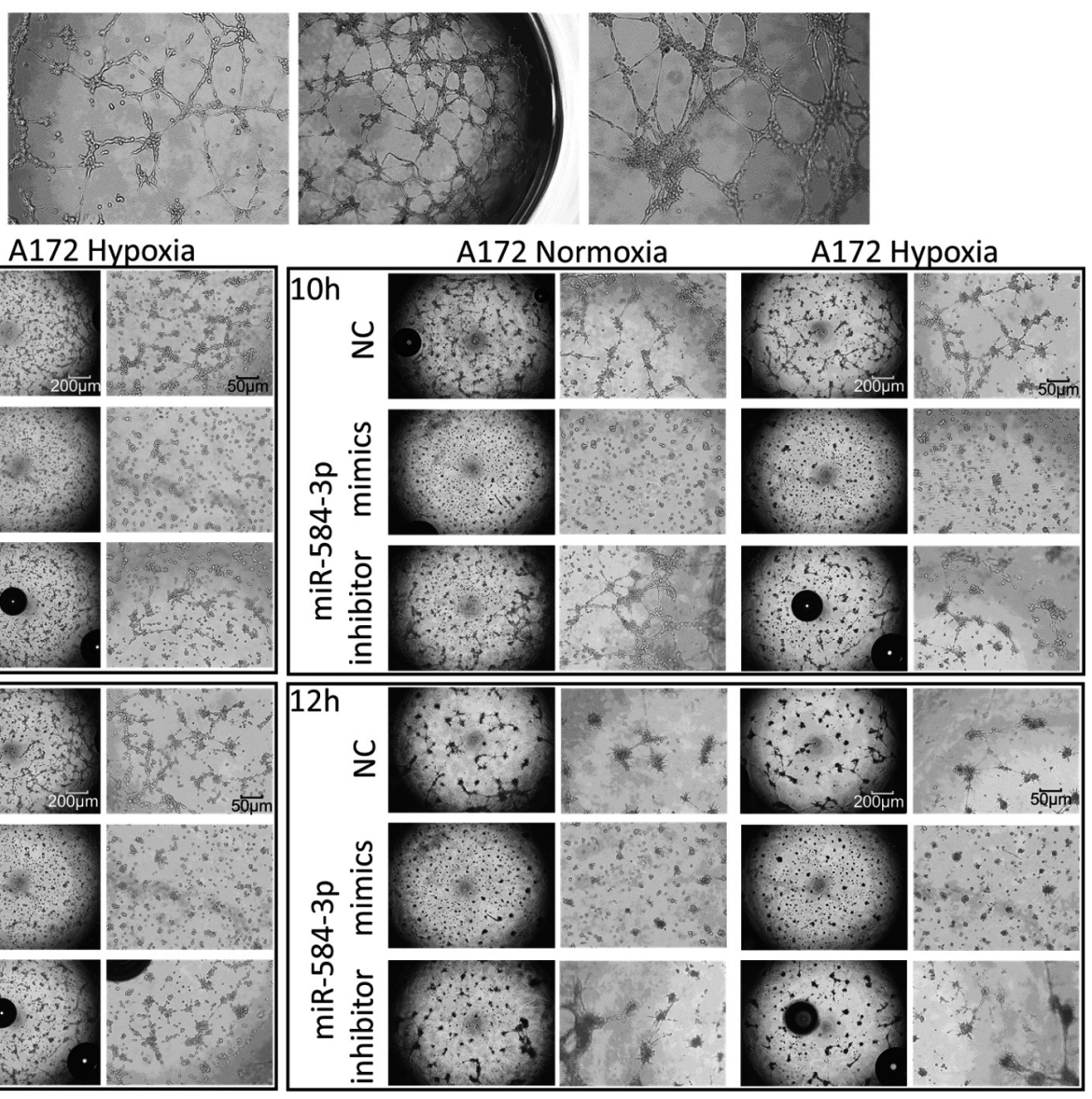

Figure 3. Over-expression of miR-584-3p paralyses hypoxia-induced VM formation in human A172 glioma cells.

(A) After transferred into wells of 96-well tissue culture plates were coated with Matrigel and 6 hours hypoxia treatment, both A172 and U87 glioma cells revealed an excessively enhanced VM formation. (B) The VM suppression effect of miR-584-3p mimics, particularly even under hypoxic conditions in A172 cells. WhilemiR-584-3p inhibitor significantly promotedA172 glioma cells' VM under normoxic and hypoxia conditions. The undisturbed VM formation initiated at $4 \mathrm{~h}$, peaked at $10 \mathrm{~h}$, and vanished after $12 \mathrm{~h}$ in normoxia control A172 cells. And miR-584-3pinhibitor further enhanced the VM structures, particularly revealed a vicarious effect of hypoxia. In contrast, miR-584-3p mimics completely blocked the VM formation throughout the experiment whether hypoxia or not. NC, negative control. 
an evident cytoskeletal change that is critical to cell motility and VM formation, suggests that miR-584-3p may hinder VM formation of glioma cells by affecting actin stress fibers formation by modulating the RhoA/ROCK pathway.

Over-expression of miR-584-3p paralyses hypoxiainduced VM formation. There is a great deal of research demonstrated that hypoxia could induced angiogenesis and VM formation. And in recent years, accumulating evidence have confirmed the pro-migratory and pro-invasive effects of hypoxia. In this regard, we tested whether miR-584-3p was involved in hypoxia-induced VM formation. Both A172 and U87 glioma cells revealed an excessively enhanced VM formation after cultured under hypoxia for 6 hours (Figure3A).

To clarify the suppressive role of miR-584-3p in hypoxia induced glioma VM formation, we investigated the timedependent effects of miR-584-3p in both A172 and U87 glioma cells. First, we observed a significant VM suppression effect of miR-584-3p mimics, particularly in hypoxic A172 cells. miR-584-3p inhibitor significantly promoted A172 glioma cell VM formation both under normoxic conditions and there was only a modest difference under hypoxia conditions (Figure 3B). Interestingly, the VM formation was dependent with time. The undisturbed VM formation initiated at $4 \mathrm{~h}$, peaked at $10 \mathrm{~h}$, and vanished after $12 \mathrm{~h}$ in normoxia control A172 cells. And miR-584-3p inhibitor further enhanced the VM structures, particularly revealed a vicarious effect of hypoxia. In contrast, miR-584-3p mimics completely blocked the VM formation both normoxia and hypoxia. In accordance with the observation in Figure 4, hypoxia significantly promoted the VM formation, and the peak-time arrived earlier to 4-6h. And for this reason, miR-584-3p inhibitor induced a more quickly subsiding of VM under hypoxia condition between 6 to $10 \mathrm{~h}$ (Figure 3B).Furthermore, we observed similar results in U87 cells, which performed a more significant phenomenon and 2 hours earlier peak-time in the whole VM formation assay (Figure S1). However, both A172 and U87 cells formed spheroids no later than 12 hours as the final stage, and the 3D structure of VM in tubule formation assay could not maintain as the spheroids formation tendency of 3D cultured tumor cells.

Taken together, our results clearly demonstrate that miR584-3p knockdown could markedly promote VM formation of human glioma cells and aggravate the hypoxia-induced VM promoting effects. While miR-584-3p over-expression could antagonize VM formation, especially hypoxia-induced VM formation on human glioma cells.

miR-584-3p antagonizes the hypoxia-induced VM formation by targeting ROCK-1. As demonstrated in Figure $3 \mathrm{~B}$, the inhibitory effect of miR-584-3p in in actin stress fiber formation suggested that miR-584-3p may block VM formation in a ROCK1-dependent manner. To investigate whether miR-584-3p and ROCK1 are involved, we utilized a ROCK1-specific inhibitor Y-27632. Firstly, we determined whether specific inhibition of the Rho-ROCK pathway using the ROCK1-specific inhibitor Y-27632 could block VM formation. A172 glioma cells pretreated with Y-27632 for $12 \mathrm{~h}$ showed decreased VM formation. What's more important is that Y-27632 treated A172 cell lost the migratory and aggregating ability as miR-584-3p over-expressed cells, despite those nonpolar filamentary indifferent pseudopod (Figure 4 middle). Secondly, the VM promoting effect of miR-584-3p inhibitor

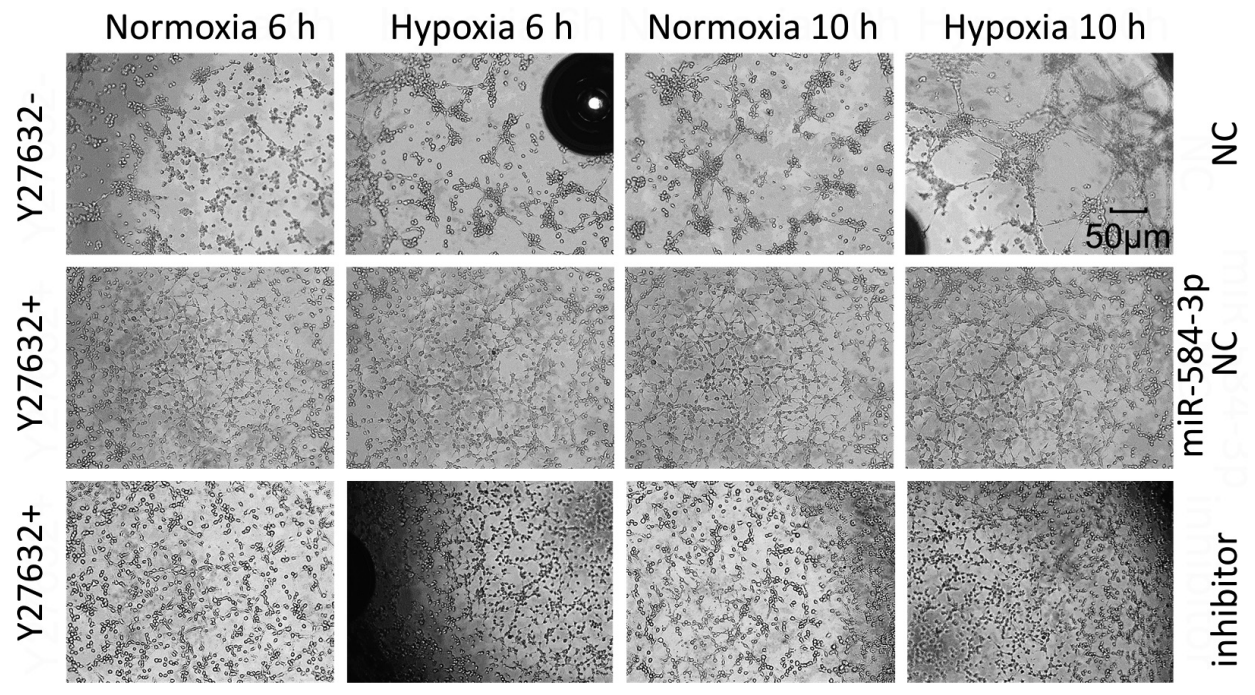

Figure 4. Specific inhibition of ROCK1 by Y-27632 blocked the VM promoting effect of the miR-584-3p inhibitor and exerted a synergistic effect with the miR-584-3p mimic.

A172 glioma cells were pretreated with Y-27632 for $12 \mathrm{~h}$, which resulted in significant inhibition of VM. The Y-27632 treated A172 cell lost the migratory and aggregating ability as miR-584-3p over-expressed cells, despite those nonpolar filamentary indifferent pseudopod (upper and middle). We pretreated the miR-584-3p knocking-down A172 cells with Y-27632 for $12 \mathrm{~h}$, and detected that the VM promoting effect of miR-584-3p inhibitor was totally blocked (lower). In addition, the hypoxia effect also blocked by ROCK1-specific inhibitor Y-27632 (right). NC, negative control. 
was totally blocked by Y-27632 pretreatment for $12 \mathrm{~h}$ (Figure 4 lower). In addition, the hypoxia induced VM formation could also be blocked by ROCK1-specific inhibitor Y-27632 (Figure 4 right). Hence, we could confirm that miR-584-3p antagonizes the hypoxia-induced VM promoting effects by targeting ROCK-1 signal pathway.

\section{Discussion}

In recent years, tumor-suppressive miRNAs has been a topic of interest for antitumor study, and accumulating evidence has demonstrated their potential of prognostic indicating and antitumor therapeutic prospects $[26,27]$. Several recent studies have confirmed numerous highly expressed miRNAs predicting prognosis for glioma patients [11, 28-30]. Meanwhile, an increasing number of tumor-suppressive miRNAs have also been discovered [31]. Here, we identified miR-584$3 p$ as a novel anti-tumor miRNA by targeting VM formation in glioma. In the present work, we firstly reported the role for miR-584-3p in preventing VM formation and its possible regulatory target in malignant glioma.

Cells undergo a variety of biological responses when subjected to ischemic and hypoxic conditions, including the activation of signaling pathways that regulate proliferation, angiogenesis, metastasis, and apoptosis. Tumor cells have adapted these pathways to survive and even grow under ischemic and hypoxic conditions. Tumor hypoxia is associated with poor prognosis and resistance to anti-tumor therapy [32]. Additionally, cell invasion, apoptosis, chemoresistance, and radiation resistance are affected by hypoxia. The extent of the influence of hypoxia on these processes makes it an attractive therapeutic strategy for glioma [33]. Cancer stem cells (CSCs) were identified as a VM-initiating cells in a variety types of cancer, and these current CSC studies provide novel insights into tumor angiogenesis and its interplay with the tumor microenvironment [34]. Although the angiogenesis capacity of GSCs has been demonstrated and the phenomenon of VM in none-GSC glioma cells has also been reported [35], but its mechanism are still unclear. Above all, vascularization is most crucial for the growth of hypoxic tumors [36], and VM which described as the non-endothelium dependent vessels in gliomas represents an important new tumor survival mechanism [23]. VM may be responsible for the failure of current anti-angiogenic therapy, and the exact mechanism remains require further study [37].

It has been previously shown that the high-grade glioma has a much severe hypoxia condition [38]. For example, the WHO grade I and II gliomas were characterized by modest cellular hypoxia ( $\mathrm{pO} 2 \mathrm{~s}>10 \%)$, grade III tumors by modestto-moderate hypoxia ( $\mathrm{pO} 2 \mathrm{~s} \approx 10 \% \sim 2.5 \%$ ), and severe hypoxia $(<0.1 \%$ oxygen) was present in some grade IV tumors [38]. Accordingly, it is conceivable that the high VM forming rate in high-grade gliomas is initiated by severe hypoxia and ischemia. The present study indicated that VM formation in glioma might be hypoxia-induced. Glioma cell lines A172 and U87 were induced from recognized WHO IV glioblastoma, and our hypoxia condition was $1 \% \mathrm{O}_{2}$, which was also conform to the actual situation in vivo.

Based on our results and previous reports, we concluded that miR-584-3p could antagonize the hypoxia-induced glioma VM formation by inhibiting migration and cytoskeleton reorganization. Because stress fiber formation is ROCK1-dependnt [25], we validated the target molecule in VM by using ROCK-1-specific inhibitor Y27632. This inhibitor reversed miR-584-3p inhibitor promoted VM formation as expected. These results demonstrated that ROCK- 1 is a potential target of miR-584-3p in regulating VM formation.

However, one limitation of this study is the small number of samples. In addition, the involvement of other key invasionassociated proteins such as Rac1, Cdc42 [39], or MMPs [40] have not been investigated. Therefore, additional studies will be required to substantiate this mechanism.

Acknowledgments: This work was supported by grants from the National Natural Science Foundation of China (NO 81101594; $81372719 ; 81172403 ; 81571284 ; 91542115)$. We thank to Pamela F, the senior editor of American Journal Experts for linguistic advice.

\section{References}

[1] OHGAKI H. Epidemiology of brain tumors. Methods Mol Biol 2009; 472: 323-342. http://dx.doi.org/10.1007/978-160327-492-0 14

[2] MCNAMARA MG, MASON WP. Antiangiogenic therapies in glioblastoma multiforme. Expert Rev Anticancer Ther 2012; 12: 643-654. http://dx.doi.org/10.1586/era.12.35

[3] VAUPEL P. Hypoxia and aggressive tumor phenotype: implications for therapy and prognosis. Oncologist 2008; 13 Suppl 3: 21-26. http://dx.doi.org/10.1634/theoncologist.13$\underline{\mathrm{S} 3-21}$

[4] MONGIARDI MP. Angiogenesis and hypoxia in glioblastoma: a focus on cancer stem cells. CNS Neurol Disord Drug Targets 2012; 11: 878-883. http://dx.doi. org/10.2174/1871527311201070878

[5] SEFTOR RE, HESS AR, SEFTOR EA, KIRSCHMANN DA, HARDY KM et al. Tumor cell vasculogenic mimicry: from controversy to therapeutic promise. Am J Pathol 2012; 181: 1115-1125. http://dx.doi.org/10.1016/j.ajpath.2012.07.013 http://dx.doi.org/10.1016/j.ajpath.2012.07.013

[6] QIAO L, LIANG N, ZHANG J, XIE J, LIU F et al. Advanced research on vasculogenic mimicry in cancer. J Cell Mol Med 2015; 19: 315-326. http://dx.doi.org/10.1111/jcmm.12496 http://dx.doi.org/10.1111/jcmm.12496

[7] DONG J, ZHAO Y, HUANG Q, FEI X, DIAO Y et al. Glioma stem/progenitor cells contribute to neovascularization via transdifferentiation. Stem Cell Rev 2011; 7: 141-152. http:// dx.doi.org/10.1007/s12015-010-9169-7 http://dx.doi. org/10.1007/s12015-010-9169-7

[8] LIU T, SUN B, ZHAO X, LI Y, GU Q et al. OCT4 expression and vasculogenic mimicry formation positively correlate with poor prognosis in human breast cancer. Int J Mol Sci 2014; 
15: 19634-19649. http://dx.doi.org/10.3390/ijms151119634 http://dx.doi.org/10.3390/ijms151119634

[9] BARTEL DP. MicroRNAs: genomics, biogenesis, mechanism, and function. Cell 2004; 116: 281-297. http://dx.doi. org/10.1016/S0092-8674(04)00045-5

[10] FILIPOWICZ W, BHATTACHARYYA SN, SONENBERG N. Mechanisms of post-transcriptional regulation by microRNAs: are the answers in sight. Nat Rev Genet 2008; 9: 102-114. http://dx.doi.org/10.1038/nrg2290

[11] ZHANG R, PANG B, XIN T, GUO H, XING Y et al. Plasma miR-221/222 Family as Novel Descriptive and Prognostic Biomarkers for Glioma. Mol Neurobiol 2015 :

[12] DEWS M, HOMAYOUNI A, YU D, MURPHY D, SEVIGNANI C et al. Augmentation of tumor angiogenesis by a Myc-activated microRNA cluster. Nat Genet 2006; 38: 1060-1065. http://dx.doi.org/10.1038/ng1855

[13] ZHAO Z, TAN X, ZHAO A, ZHU L, YIN B et al. microRNA-214-mediated UBC9 expression in glioma. BMB Rep 2012; 45: 641-646. http://dx.doi.org/10.5483/ BMBRep.2012.45.11.097

[14] MA L, YOUNG J, PRABHALA H, PAN E, MESTDAGH P et al. miR-9, a MYC/MYCN-activated microRNA, regulates E-cadherin and cancer metastasis. Nat Cell Biol 2010; 12: 247-256. http://dx.doi.org/10.1038/ncb2024

[15] ZHAO N, SUN BC, ZHAO XL, WANG Y, SUN HZ et al. Changes in microRNAs associated with Twist- 1 and Bcl-2 overexpression identify signaling pathways. Exp Mol Pathol 2015; 99: 524-532. http://dx.doi.org/10.1016/j.yexmp.2015.08.018 http://dx.doi.org/10.1016/j.yexmp.2015.08.018

[16] GAO R, CAI C, GAN J, YANG X, SHUANG Z et al. miR-1236 down-regulates alpha-fetoprotein, thus causing PTEN accumulation, which inhibits the PI3K/Akt pathway and malignant phenotype in hepatoma cells. Oncotarget 2015; 6: 6014-6028. http://dx.doi.org/10.18632/oncotarget.3338

[17] WAN HY, LI QQ, ZHANG Y, TIAN W, LI YN et al. MiR-124 represses vasculogenic mimicry and cell motility by targeting amotL1 in cervical cancer cells. Cancer Lett 2014; 355: 148-158. http://dx.doi.org/10.1016/j.canlet.2014.09.005 http://dx.doi.org/10.1016/j.canlet.2014.09.005

[18] SUN Q, ZOU X, ZHANG T, SHEN J, YIN Y et al. The role of miR-200a in vasculogenic mimicry and its clinical significance in ovarian cancer. Gynecol Oncol 2014; 132: 730-738. http://dx.doi.org/10.1016/j.ygyno.2014.01.047 http://dx.doi. org/10.1016/j.ygyno.2014.01.047

[19] SONG Y, MU L, HAN X, LI Q, DONG B et al. MicroRNA-9 inhibits vasculogenic mimicry of glioma cell lines by suppressing Stathmin expression. J Neurooncol 2013; 115: 381-390. http://dx.doi.org/10.1007/s11060-013-1245-9 http://dx.doi. org/10.1007/s11060-013-1245-9

[20] WENG C, DONG H, CHEN G, ZHAI Y, BAI R et al. miR409-3p inhibits HT1080 cell proliferation, vascularization and metastasis by targeting angiogenin. Cancer Lett 2012; 323: 171-179. http://dx.doi.org/10.1016/j.canlet.2012.04.010 http://dx.doi.org/10.1016/j.canlet.2012.04.010

[21] WU N, ZHAO X, LIU M, LIU H, YAO W et al. Role of microRNA-26b in glioma development and its mediated regulation on EphA2. PLoS One 2011; 6: e16264. http://dx.doi. org/10.1371/journal.pone.0016264 http://dx.doi.org/10.1371/ journal.pone.0016264

[22] SHEVDE LA, METGE BJ, MITRA A, XI Y, JU J et al. Spheroidforming subpopulation of breast cancer cells demonstrates vasculogenic mimicry via hsa-miR-299-5p regulated de novo expression of osteopontin. J Cell Mol Med 2010; 14: 16931706. http://dx.doi.org/10.1111/j.1582-4934.2009.00821.x http://dx.doi.org/10.1111/j.1582-4934.2009.00821.x

[23] YUE WY, CHEN ZP. Does vasculogenic mimicry exist in astrocytoma. J Histochem Cytochem 2005; 53: 997-1002. http://dx.doi.org/10.1369/jhc.4A6521.2005 http://dx.doi. org/10.1369/jhc.4A6521.2005

[24] FOLBERG R, HENDRIX MJ, MANIOTIS AJ. Vasculogenic mimicry and tumor angiogenesis. Am J Pathol 2000; 156: 361-381. http://dx.doi.org/10.1016/S0002-9440(10)64739-6 http://dx.doi.org/10.1016/S0002-9440(10)64739-6

[25] BISHOP AL, HALL A. Rho GTPases and their effector proteins. Biochem J 2000; 348 Pt 2: 241-255.

[26] YAN W, LI R, LIU Y, YANG P, WANG Z et al. MicroRNA expression patterns in the malignant progression of gliomas and a 5-microRNA signature for prognosis. Oncotarget 2014; 5: 12908-12915. http://dx.doi.org/10.18632/oncotarget.2679

[27] AUFFINGER B, THACI B, AHMED A, ULASOV I, LESNIAK MS. MicroRNA targeting as a therapeutic strategy against glioma. Curr Mol Med 2013; 13: 535-542. http://dx.doi. org/10.2174/1566524011313040006

[28] YANG CH, YUE J, PFEFFER SR, FAN M, PAULUS E et al. MicroRNA-21 promotes glioblastoma tumorigenesis by down-regulating insulin-like growth factor-binding protein-3 (IGFBP3). J Biol Chem 2014; 289: 25079-25087. http://dx.doi. org/10.1074/jbc.M114.593863

[29] BARBANO R, PALUMBO O, PASCULLI B, GALASSO M, VOLINIA $S$ et al. A miRNA signature for defining aggressive phenotype and prognosis in gliomas. PLoS One 2014; 9: e108950. http://dx.doi.org/10.1371/journal.pone.0108950

[30] LAI NS, WU DG, FANG XG, LIN YC, CHEN SS et al. Serum microRNA-210 as a potential noninvasive biomarker for the diagnosis and prognosis of glioma. Br J Cancer 2015 :

[31] QUE T, SONG Y, LIU Z, ZHENG S, LONG H et al. Decreased miRNA-637 is an unfavorable prognosis marker and promotes glioma cell growth, migration and invasion via direct targeting Akt1. Oncogene 2015; 0:

[32] HARRIS AL. Hypoxia--a key regulatory factor in tumour growth. Nat Rev Cancer 2002; 2: 38-47. http://dx.doi. org/10.1038/nrc704

[33] JENSEN RL. Brain tumor hypoxia: tumorigenesis, angiogenesis, imaging, pseudoprogression, and as a therapeutic target. J Neurooncol 2009; 92: 317-335. http://dx.doi.org/10.1007/ $\underline{\text { s11060-009-9827-2 }}$

[34] FAN YL, ZHENG M, TANG YL, LIANG XH. A new perspective of vasculogenic mimicry: EMT and cancer stem cells (Review). Oncol Lett 2013; 6: 1174-1180. http:// dx.doi.org/10.3892/ol.2013.1555 http://dx.doi.org/10.3892/ ol.2013.1555

[35] SMITH SJ, WARD JH, TAN C, GRUNDY RG, RAHMAN R. Endothelial-like malignant glioma cells in dynamic three dimensional culture identifies a role for VEGF and 
FGFR in a tumor-derived angiogenic response. Oncotarget 2015; 6: 22191-22205. http://dx.doi.org/10.18632/oncotarget.4339

[36] JHAVERI N, CHEN TC, HOFMAN FM. Tumor vasculature and glioma stem cells: Contributions to glioma progression. Cancer Lett 2014 : http://dx.doi. org/10.1016/j.canlet.2014.12.028 http://dx.doi.org/10.1016/j. canlet.2014.12.028

[37] MAO JM, LIU J, GUO G, MAO XG, LI CX. Glioblastoma vasculogenic mimicry: signaling pathways progression and potential anti-angiogenesis targets. Biomark Res 2015; 3: 8. http://dx.doi.org/10.1186/s40364-015-0034-3 http://dx.doi. org/10.1186/s40364-015-0034-3
[38] EVANS SM, JUDY KD, DUNPHY I, JENKINS WT, HWANG WT et al. Hypoxia is important in the biology and aggression of human glial brain tumors. Clin Cancer Res 2004; 10: 8177-8184. http://dx.doi.org/10.1158/1078-0432.CCR04-1081 http://dx.doi.org/10.1158/1078-0432.CCR-04-1081

[39] CARDAMA GA, GONZALEZ N, CIARLANTINI M, GANDOLFI DL, COMIN MJ et al. Proapoptotic and antiinvasive activity of Rac1 small molecule inhibitors on malignant glioma cells. Onco Targets Ther 2014; 7: 2021-2033.

[40] KONNECKE H, BECHMANN I. The role of microglia and matrix metalloproteinases involvement in neuroinflammation and gliomas. Clin Dev Immunol 2013; 2013: 914104. http:// dx.doi.org/10.1155/2013/914104 

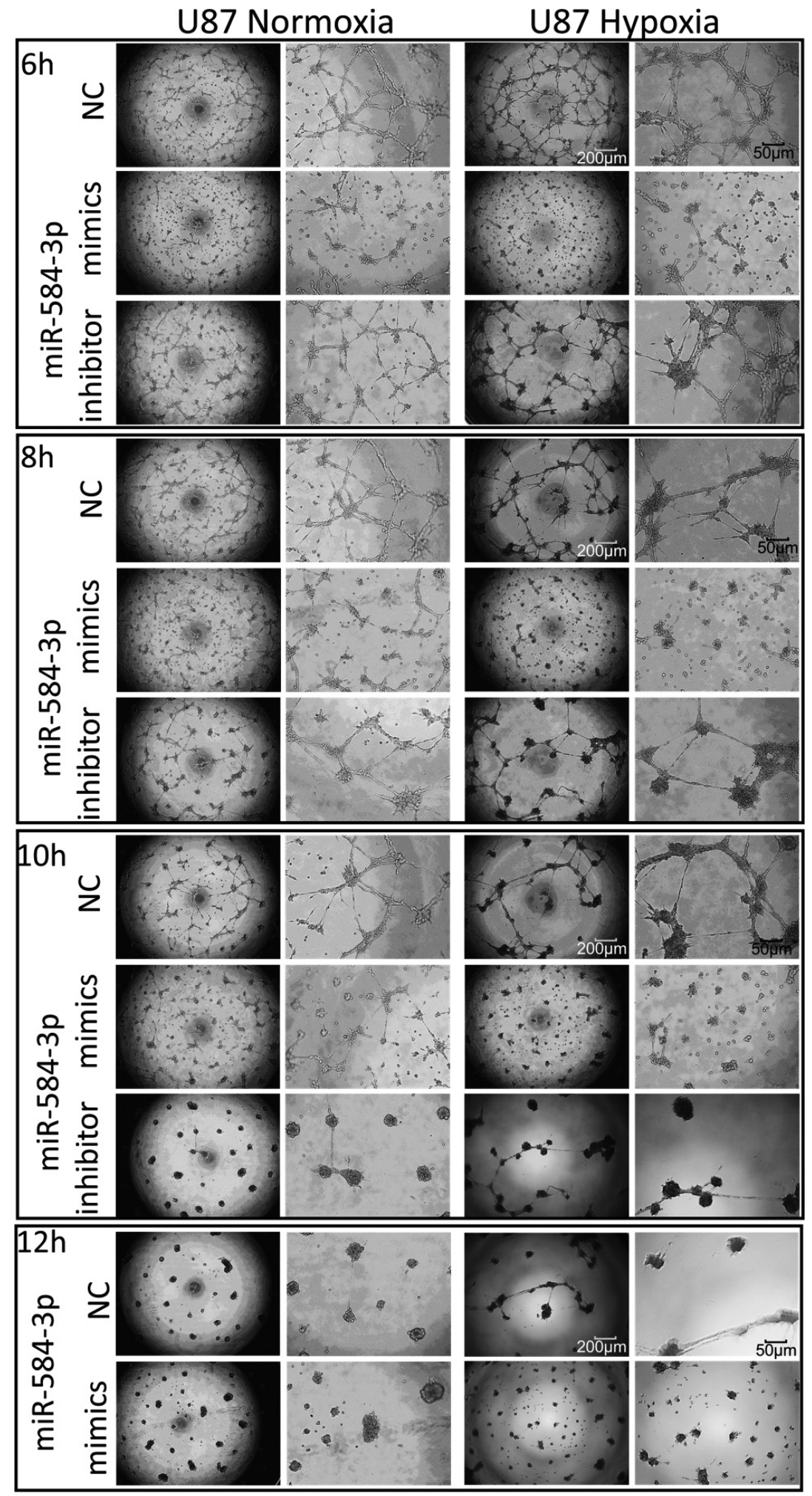

Figure S1 Over-expression of miR-584-3p paralyses hypoxia-induced VM formation in human U87 glioma cells.

The VM suppression effect of miR-584-3p mimics, particularly even under hypoxic conditions in U87 cells. WhilemiR-584-3p inhibitor significantly promoted U87 glioma cells' VM under normoxic and hypoxia conditions. The undisturbed VM formation initiated before $6 \mathrm{~h}$, peaked at $8 \mathrm{~h}$, and vanished after 12h in normoxia control U87 cells. And miR-584-3p inhibitor further enhanced the VM structures, particularly revealed a vicarious effect of hypoxia. In contrast, miR-584-3p mimics completely blocked the VM formation throughout the experiment whether hypoxia or not. NC, negative control. 